8. Hertzig ME 1981 Neurological "soft" signs in low-birthweight children. Dev Med Child Neurol 23:778

9. Reuben RN, Bakwin H 1968 Developmental clumsiness. Pediatr Clin N Am 15:601

10. Richardson S, Birch H, Grabie E, Yoder K 1972 The behavior of children in school who were severely malnourished in the first two years of life. J Health Soc Behav 13:276
11. Rie ED, Rie HE, Stewart S, Rettemniek SC 1978 An analysis of neurological soft signs in children with learning problems. Brain Language 6:32

12. Rutter M, Graham P, Yule M 1970 A Neuropsychiatric Study in Childhood: Clinics in Developmental Medicine 35/36. London, SIMP with Heinemann 13. Shapiro T, Burkes L, Petty T, Ranz J 1978 Consistency of "nonfocal" neurological signs. J Am Acad Child Psychiat 17:70

\title{
Hypoxia Stimulates Prostacyclin Synthesis by Neonatal Lungs
}

\author{
ROBERT S. GREEN AND CHARLES W. LEFFLER \\ Departments of Pediatrics (Section of Neonatology-Perinatology) and Physiology and Biophysics, The University \\ of Tennessee, Center for the Health Sciences, Memphis, Tennessee 38163
}

\section{Summary}

Inhibition of prostaglandin cyclooxygenase augments hypoxic pulmonary vasoconstriction. We used a neonatal lamb lung preparation perfused with Krebs' bicarbonate buffer to characterize and quantify prostanoids produced by the pulmonary vasculature from endogenous arachidonic acid in the absence of formed blood elements during ventilation with normoxic and hypoxic gas mixtures. Prostaglandin $(P G) I_{2}$ synthesis increased from $6.4 \pm 2.7$ $\mathrm{ng} / \mathrm{min}(\mathrm{SEM})$ during normoxic ventilation to $14.3 \pm 5.4 \mathrm{ng} / \mathrm{min}$ during hypoxia and returned to $4.7 \pm 1.2 \mathrm{ng} / \mathrm{min}$ with resumption of normoxia. These data demonstrate that hypoxia stimulates pulmonary vascular synthesis of prostaglandin $I_{2}$ from endogenous substrate in neonatal lambs and suggest that the augmentation of hypoxic pulmonary vasoconstriction by prostaglandin cyclooxygenase inhibition is due, at least in part, to interference with the synthesis of this vasodilator prostanoid.

\section{Abbreviations}

PG, prostanoid

PGI 2 , prostacyclin

TXB $_{2}$, thromboxane $\mathbf{B}_{2}$

Inhibition of prostaglandin cyclooxygenase augments hypoxic pulmonary vasoconstriction in adult mammals of several species $(1,12,24,27,28)$. A possible explanation for this observation is that hypoxia or hypoxic pulmonary vasoconstriction induces the

Received December 7,1983.

Address correspondence to: Robert S. Green, M.D., Newborn Center, 853 Jefferson, Room 301, Memphis. TN 38163.

This work was done during the tenure of an Established Investigatorship from the American Heart Association (C.W.I.) and with funds contributed in part by the Tennessee Affiliate. The research was supported in part by National Institutes of Health Grant HL 22639, a Grant-in-Aid from the American Heart Association with funds contributed in part by the Tennessee Affiliate, a Grant-in-Aid from the Tennessee Lung Association, and a Biomedical Research Support Grant from The University of Tennessee College of Medicine. These data were reported at the annual meeting of the Southern Society for Pediatric Research, January 27, 1983, New Orleans, LA. synthesis of a vasodilator PG that reduces the vasoconstriction. Inhibition of PG synthesis would remove this vasodilator PG and, thus, increase the hypoxic constriction. Indirect evidence supporting this hypothesis in the neonate includes the observations that: 1) $\mathrm{PGI}_{2}$ is the most abundant $\mathrm{PG}$ produced by fetal bovine pulmonary arterial slices $(22) ; 2$ ) under normoxic conditions, $\mathrm{PGI}_{2}$ is the most abundant $\mathrm{PG}$ produced by the newly ventilated neonatal lamb lung $(10,11) ; 3) \mathrm{PGI}_{2}$ is a pulmonary vasodilator in the fetal and neonatal lamb $(3,9,13)$, and its vasodilatory effect on the neonatal pulmonary vasculature is more evident during hypoxic pulmonary vasoconstriction (13); and 4) hypoxic pulmonary vasoconstriction in premature and term neonatal goats is augmented by indomethacin, an inhibitor of $P G$ synthesis (23). In the present study, we used a neonatal lamb lung preparation perfused with Krebs' bicarbonate buffer to characterize and quantify prostanoids produced by the pulmonary vasculature from endogenous arachidonic acid in the absence of formed blood elements. Pulmonary perfusate was collected during ventilation with normoxic and hypoxic gas mixtures. Analysis of these perfusates allowed determination of the effect of hypoxic pulmonary vasoconstriction on pulmonary vascular prostanoid synthesis.

\section{MATERIALS AND METHODS}

Animal preparation. Fourteen neonatal lambs [ $10.7 \pm 2.0$ days old $(\mathrm{SEM}) ; 5.5 \pm 1.6 \mathrm{~kg}$ ) were anesthetized with $50 \mathrm{mg} / \mathrm{kg} \alpha$ chloralose IV. A tracheostomy was performed, and ventilation with room air was begun using a constant volume ventilator. A left thoracotomy was performed and the left lung was removed, leaving the mediastinum intact. Consequently, the right lung, which was to be perfused, was not exposed to the environment. The tidal volume was reduced by approximately $40 \%$, the ductus arteriosus was ligated, and the left atrium was cannulated with a Teflon catheter. A repeat dose of $10 \mathrm{mg} / \mathrm{kg} \alpha$-chloralose was administered, and the pulmonary artery was ligated and cannulated, thus sacrificing the animal. Perfusion of the lung with $37^{\circ} \mathrm{C}$

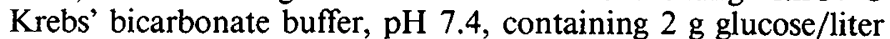
equilibrated with $3 \% \mathrm{O}_{2}, 5 \% \mathrm{CO}_{2}, 92 \% \mathrm{~N}_{2}$ was then begun using 
a roller pump. The ventilating gas mixture was changed to $20 \%$ $\mathrm{O}_{2}, 5 \% \mathrm{CO}_{2}, 75 \% \mathrm{~N}_{2}$. The heart was clamped at the atrioventricular valves so that all perfusate exited through the left atrial catheter. The perfusate was not recirculated. During an initial 15-min equilibration period, formed elements cleared from the perfusate. A constant flow was maintained so that changes in pressure reflected changes in resistance. Flow was monitored electromagnetically. Pressure was monitored with a fluid-filled pressure transducer connected to a side arm of the inflow circuit just proximal to the pulmonary arterial catheter. Both signals were amplified and recorded with a direct-writing recorder.

Experimental protocol. After the 15-min equilibration period, pulmonary venous effluent was collected for $10 \mathrm{~min}$. The ventilator gas mixture was then changed to $3 \% \mathrm{O}_{2}, 5 \% \mathrm{CO}_{2}, 92 \% \mathrm{~N}_{2}$ reducing the pulmonary venous $\mathrm{PO}_{2}$ from 85 to $33 \mathrm{~mm} \mathrm{Hg}$. One minute after the initiation of hypoxic ventilation, a second 10 min collection was begun. At the conclusion of this collection, the ventilating gas mixture was returned to $20 \% \mathrm{O}_{2}, 5 \% \mathrm{CO}_{2}$, $75 \% \mathrm{~N}_{2}$, and $10 \mathrm{~min}$ were allowed for return to normoxic conditions. Then a third 10-min collection was performed. The collected perfusates were stored at $-60^{\circ} \mathrm{C}$ for later analysis.

Prostanoid analysis. The methods used are a modification of those which have been described and verified previously $(8,10)$. Each sample was treated thusly. The pulmonary venous effluents were allowed to thaw and $600 \mathrm{ng} \mathrm{PGA}_{2}$ were added to each as an internal standard. A sample containing $600 \mathrm{ng} \mathrm{PGA}_{2}$ and known amounts of $\mathrm{PGE}_{2}, 6$-keto-PGF ${ }_{1 \alpha}, \mathrm{TXB}_{2}$, and 6,15-diketo13,14-dihydro-PGF ${ }_{1 \alpha}$ (Upjohn) were processed with each set of samples. Following acidification to $\mathrm{pH} 3$ with formic acid, each sample was applied to an octadecylsilyl cartridge (Sep-Pak, Waters Associates, Inc.) that previously had been washed and wetted with $30 \mathrm{ml}$ acetone, $30 \mathrm{ml}$ hexane, $60 \mathrm{ml}$ methanol, and $60 \mathrm{ml}$ of water. The Sep-Pak containing the sample was washed with $20 \mathrm{ml}$ of water followed by $20 \mathrm{ml}$ petroleum ether, both of which were discarded. The PGs were eluted with $10 \mathrm{ml}$ of ethyl acetate [modified from Powell (16)]. Fifteen $\mathrm{ml}$ of toluene was added to the $10 \mathrm{ml}$ of ethyl acetate and the mixture was applied to a silica column (Adsorbosil, $8 \mathrm{~cm} \times 5 \mathrm{~mm}$, Anspec, Inc.). PGs on the column were washed with $25 \mathrm{ml}$ of $60: 40$ toluene:ethyl acetate (discarded). PGs were eluted with $15 \mathrm{ml}$ of $60: 40: 5: 1$ toluene:ethyl acetate:methanol:formic acid. The eluant was evaporated under vacuum and the invisible residue was transferred to a reaction vial for derivatization prior to analysis by gas chromatography with electron capture detection. Derivatization to pentafluorobenzyloximes of PG methyl ester trimethylsilyl ethers was accomplished as described perviously $(8,10)$. Analyses were performed on a Perkin-Elmer Sigma 4, equipped with heated splitless injector and ${ }^{63} \mathrm{Ni}$ electron capture detector. Gas-liquid chromatography was performed using $0.5 \mathrm{~mm} \times 25 \mathrm{~m}$ SCOT OV 101 capillaries (Scientific Glass Engineering) at $250^{\circ} \mathrm{C}$ and a column pressure of $140 \mathrm{~mm} \mathrm{Hg}$, with helium as the carrier. Injector and detector temperatures were $375^{\circ} \mathrm{C}$.

Details and verification of methods used for quantification and mass spectrometric confirmation of derivatized standard structures have been published elsewhere (8). Briefly, the relative detector responses to $\mathrm{PGA}_{2}$ and other $\mathrm{PGs}$ were determined from simultaneous extraction plus derivatization of known quantities of each. For each PG, a factor $(\Sigma)$ encompassing all differences between PGs with respect to extraction, derivatization, and detector response, was calculated: $\Sigma=\left(W_{x} \cdot H_{A}\right) /\left(H_{x} \cdot W_{A}\right)$, where $W_{x}$ is the quantity of $\mathrm{PG}_{x}, H_{x}$ is the detector response to $\mathrm{PG}_{\lambda}$, $W_{A}$ is the quantity of $\mathrm{PGA}_{2}$, and $H_{A}$ is the detector response to $\mathrm{PGA}_{2}$. PGs were quantified in the samples by comparison to $\mathrm{PGA}_{2}$ added as the internal standard: $W_{x}=H_{\lambda} \cdot W_{A} \cdot \Sigma \cdot H_{A}^{-1}$.

This method $(8,10)$ is capable of quantifying as little as $5 \mathrm{ng}$ of $\mathrm{PGD}_{2}, \mathrm{PGE}_{2}$, 6-keto-PGF $\mathrm{PG}_{1 \times}, \mathrm{TXB}_{2}, 6$ 6-keto-PGE $\mathrm{PG}_{1}$, or 6,15diketo-13,14-dihydro-PGF ${ }_{1, x}$ in the initial fluid sample.

Statistics. Results are reported as the mean \pm standard error of the mean for 14 animals. Hemodynamic data and PG production were analyzed using a two-way analysis of variance allowing partitioning of variation into that due to treatments (normoxia, hypoxia, normoxia), replications (14 animals), and residual variation. The $F$ for the effect of treatments was defined as the mean square for treatments divided by the mean square for residuals with significance defined as $P<0.05$. When the effect of treatments was significant, the mean value of a hemodynamic or $\mathrm{PG}$ variable during hypoxia was compared with the average of the pre- and posthypoxia means of that variable using the $t$-test for planned comparisons among means as described by Snedecor and Cochran (20).

\section{RESULTS}

The results of these experiments are illustrated in Figure 1. Constant flow was maintained throughout each experiment, the mean flow being $2.2 \pm 0.3 \mathrm{ml} / \mathrm{min} \cdot \mathrm{kg}$ body weight or $11.2 \pm$ $1.1 \mathrm{ml} / \mathrm{min}$. Hypoxia resulted in a significant rise of pulmonary perfusion pressure from $10.0 \pm 2.3$ to $14.1 \pm 3.8 \mathrm{~mm} \mathrm{Hg}$, with return to $10.9 \pm 2.5 \mathrm{~mm} \mathrm{Hg}$ with resumption of normoxic ventilation. Calculated pulmonary vascular resistance increased significantly from a baseline during normoxia of $4.7 \pm 0.8$ to 5.9 $\pm 0.9 \mathrm{~mm} \mathrm{Hg} /(\mathrm{ml} / \mathrm{kg} \cdot \mathrm{min})$ during hypoxia, returning to $4.9 \pm$ $0.9 \mathrm{~mm} \mathrm{Hg} /(\mathrm{ml} / \mathrm{kg} \cdot \mathrm{min})$ with return to normoxia. $\mathrm{PGI}_{2}$ synthesis, measured as 6-ketoPGF ${ }_{1 a r}$ increased significantly from $6.4 \pm$ $2.7 \mathrm{ng} / \mathrm{min}$ during normoxic ventilation to $14.3 \pm 5.4 \mathrm{ng} / \mathrm{min}$ during hypoxia and returned to $4.7 \pm 1.2 \mathrm{ng} / \mathrm{min}$ with resumption of normoxia. A metabolite of $\mathrm{PGI}_{2}$, co-migrating on the gas chromatographic column with synthetic 6,15-diketo-13,14-dihydro $\mathrm{PGF}_{\mathrm{l}}$, was detected sporadically and in concentrations far less than that of 6-keto-PGF ${ }_{1 \ll r}$. Thromboxane $\mathrm{A}_{2}$ (as thromboxane $\mathrm{B}_{2}$ ) was the only other prostanoid detected, and its synthesis did not change significantly with alveolar hypoxia $(2.8$

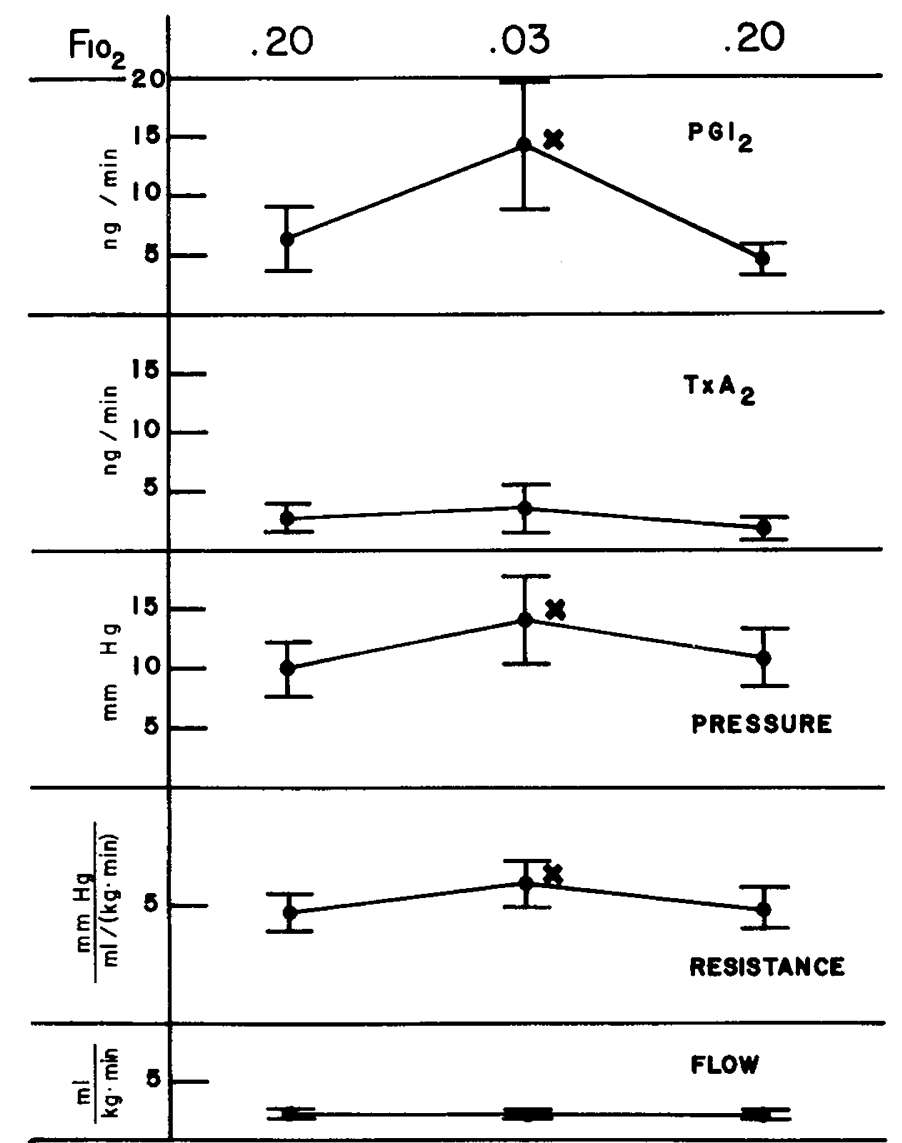

Fig. 1. Hypoxic pulmonary vasoconstriction and prostanoid synthesis in neonatal lambs. Bars indicate \pm SEM. Symbol indicates significant difference between hypoxic period and average of pre- and posthypoxic control periods $(P<0.05 ; n=14)$. 
Table 1. Analysis of variance tables for two-way classification

\begin{tabular}{|c|c|c|c|c|c|}
\hline $\begin{array}{c}\text { Sources of } \\
\text { variation }\end{array}$ & $d f$ & $\begin{array}{l}\text { Sum of } \\
\text { squares }\end{array}$ & $\begin{array}{c}\text { Mean } \\
\text { square }\end{array}$ & $F$ & $P$ \\
\hline \multicolumn{6}{|l|}{$\mathrm{PGI}_{2}$} \\
\hline Replications* & 13 & 4060.30 & 312.33 & \multirow[b]{3}{*}{3.38} & \multirow[b]{3}{*}{$<0.05$} \\
\hline Treatments $\dagger$ & 2 & 734.16 & 367.08 & & \\
\hline Residuals & 26 & 2820.58 & 108.48 & & \\
\hline Total & 41 & 7615.04 & & & \\
\hline \multicolumn{6}{|l|}{$\mathrm{TxA}_{2}$} \\
\hline Replications & 13 & 691.20 & 53.17 & \multirow{4}{*}{0.62} & \multirow{4}{*}{ N.S. } \\
\hline Treatments & 2 & 20.72 & 10.36 & & \\
\hline & & & & & \\
\hline Residuals & 26 & 430.86 & 16.57 & & \\
\hline Total & 41 & 1142.78 & & & \\
\hline \multicolumn{6}{|l|}{ Pressure } \\
\hline Replications & 13 & 4321.37 & 332.41 & \multirow{4}{*}{3.66} & \multirow{4}{*}{$<0.05$} \\
\hline Treatments & 2 & 126.70 & 63.35 & & \\
\hline & & & & & \\
\hline Residuals & 26 & 450.34 & 17.32 & & \\
\hline Total & 41 & 4898.41 & & & \\
\hline \multicolumn{6}{|l|}{ Resistance } \\
\hline Replications & 13 & 400.81 & 30.83 & \multirow{4}{*}{6.16} & \multirow{4}{*}{$<0.01$} \\
\hline Treatments & 2 & 11.34 & 5.67 & & \\
\hline & & & & & \\
\hline Residuals & 26 & 23.87 & 0.92 & & \\
\hline Total & 41 & 436.02 & & & \\
\hline
\end{tabular}

* Fourteen lambs.

$\dagger$ Three treatments: normoxia, hypoxia, normoxia.

$\pm 1.1 \mathrm{ng} / \mathrm{min}$ prehypoxia; $3.6 \pm 2.0 \mathrm{ng} / \mathrm{min}$ during hypoxia; 1.8 $\pm 0.9 \mathrm{ng} / \mathrm{min}$ posthypoxia). Analysis of variance tables for $\mathrm{PGI}_{2}$, thromboxane $A_{2}$, pressure, and resistance are shown in Table 1 .

\section{DISCUSSION}

The role of PGs in hypoxic pulmonary vasoconstriction has been of considerable interest since Said et al. (18) first suggested that alveolar hypoxia may induce PG synthesis. Since then, several groups have shown that inhibition of PG synthesis with a variety of cyclooxygenase inhibitors augments hypoxic pulmonary vasoconstriction $(1,12,23,24,27,28)$ in several species including newly ventilated and several-day-old neonatal goats (23). Augmentation of hypoxic pulmonary vasoconstriction following prostaglandin cyclooxygenase inhibition suggests that either alveolar hypoxia is associated with increased synthesis of a vasodilator $P G$ by the pulmonary vasculature which blunts hypoxic pulmonary vasoconstriction or that cyclooxygenase inhibition diverts arachidonic acid to the lipoxygenase pathway causing increased synthesis of a vasoconstrictor leukotriene.

$\mathrm{PGI}_{2}$ is a potent pulmonary vasodilator in the perinatal period $(3,9,13)$ and is the major PG synthesized from endogenous arachidonic acid by the perinatal pulmonary vasculature under normoxic conditions $(10,11)$. The present study demonstrates that hypoxic pulmonary vasoconstriction is associated with an increased synthesis of $\mathrm{PGI}_{2}$ from endogenous substrate in the neonatal lamb pulmonary vasculature. These data are consistent with previous studies showing that PG synthesis inhibition augments hypoxic pulmonary vasoconstriction, probably by inhibiting the synthesis of the vasodilator $\mathrm{PG}, \mathrm{PGI}_{2}$. Further, the ability of cyclooxygenase inhibitors to block the pulmonary vasoconstrictor response to exogenous arachidonic acid $(6,12)$ seems to argue against an important role of a vasoconstrictor leukotriene in the regulation of pulmonary vascular resistance.
Initial efforts by other workers at demonstrating the presence of and identifying a vasodilator PG employed classical tissue cascade bioassay techniques and radioimmunoassays of PGE and $\mathrm{PGF}_{2 c r}(19,25,29)$. Augmentation of $\mathrm{PG}$ synthesis by hypoxic pulmonary vasoconstriction was not detected in these studies. The radioimmunoassays used would not have detected $\mathrm{PGI}_{2}$. Furthermore, although $\mathrm{PGI}_{2}$ was first identified by bioassay, the small quantities of $\mathrm{PGI}_{2}$ produced by the pulmonary vasculature and the spontaneous hydrolysis of $\mathrm{PGI}_{2}$ to 6-keto$\mathrm{PGF}_{1, r}$ to which bioassay tissue respond poorly, may have hindered the detection of $\mathrm{PGI}_{2}$ by the bioassay tissues. Supporting this idea are the observations of Mullane et al. (15) that infusions of arachidonic acid cause pulmonary vasodilation due to bioassayable $\mathrm{PGI}_{2}$; infusion of arachidonic acid would allow for synthesis of considerably more $\mathrm{PGI}_{2}$ by the pulmonary vasculature than could be produced from endogenous arachidonic acid and thus would facilitate detection of $\mathrm{PGI}_{2}$ by bioassay.

The techniques employed in the present study were designed to allow detection and quantification of the small quantities of $\mathrm{PGI}_{2}$ produced by the pulmonary vasculature from endogenous arachidonic acid by collecting all of the pulmonary perfusate over 10-min periods and concentrating the PGs thus collected.

Voelkel et al. (26) infused radioactively labeled arachidonic acid into perfused adult rat lungs, thus labeling the endogenous arachidonic acid pool. They subsequently measured increased release of the radioactive label with hypoxic pulmonary vasoconstriction and identified $\mathrm{PGI}_{2}$ as the major labeled PG. Hamasaki et al. (4) found that hypoxia stimulates $\mathrm{PGI}_{2}$ synthesis from endogenous arachidonic acid in homogenates of adult dog lung. These results are consistent with those of the present study performed on neonatal lamb lungs.

Effects of arachidonic acid, the precursor of $\mathrm{PGI}_{2}$ and thromboxane $A_{2}$, on hypoxic pulmonary vasoconstriction have been variable with both dilation (2) and further constriction (6) described depending upon the experimental circumstances. Infusion of large quantities of exogenous arachidonic acid per unit time into the pulmonary circulation has a vasoconstrictor effect $(5,7,12)$ and augments the constriction caused by alveolar hypoxia (6) or by 15 -methyl-PGF - $_{2 k}(21)$. On the other hand, Spannhake et al. (21) were able to produce pulmonary vasodilation by slowly infusing small quantities of arachidonic acid when pulmonary vascular tone was increased with either hypoxia or 15-methyl-PGF $F_{2 k}$. Slow infusion of arachidonic acid may allow for more complete conversion of the precursor to $\mathrm{PGI}_{2}$ without producing excessive vasoconstrictor cyclic endoperoxides and thromboxane $A_{2}$. Thus, Gerber et al. (2) reported that slow arachidonic acid infusion reduces hypoxic pulmonary vasoconstriction and identified $\mathrm{PGI}_{2}$ in the pulmonary venous effluent. These observations are consistent with the results of the present study.

Rubin and Lazar (17) have reported recently that inhibition of hypoxic pulmonary vasoconstriction by hydralazine is prevented by indomethacin. Their data are consistent with ours but suggest that alveolar hypoxia alone does not stimulate prostacyclin synthesis maximally, since hydralazine appears to further reduce hypoxic pulmonary vasoconstriction by a PG-mediated mechanism.

Recently, Moon et al. (14) were able to reduce hypoxic pulmonary vasoconstriction in adult dogs by infusing arachidonic acid, and they detected an increase in the ratio of aortic to pulmonary arterial $\mathrm{PGI}_{2}$ concentration. However, these workers were unable to detect a change in $\mathrm{PGI}_{2}$ synthesis from endogenous substrate during alveolar hypoxia. This latter result differs from our own and could represent species or age differences.

In summary, the present study demonstrates that hypoxia stimulates pulmonary vascular synthesis of $\mathrm{PGI}_{2}$ from endogenous substrate in neonatal lambs. These findings suggest that the augmentation of hypoxic pulmonary vasoconstriction by prostaglandin cyclooxygenase inhibition is due, at least in part, to interference with the synthesis of this vasodilator prostanoid. 
Acknowledgments. The authors thank Randy Jerkins, Patti Jessup, and Mildred Jackson for their expert technical help and Rosalind Griffin for secretarial assistance.

\section{REFERENCES}

1. Alexander JM, Nyby MD, Jasberg KA 1977 Prostaglandin synthesis inhibition restores hypoxic pulmonary vasoconstriction. J Appl Physiol Respir Environ Exercise Physiol 42:903

2. Gerber JG, Voelkel N, Nies AS, McMurtry IF, Reeves JT 1980 Moderation of hypoxic vasoconstriction by infused arachidonic acid: role of $\mathrm{PGI}_{2} . \mathrm{J}$ Appl Physiol Respir Environ Exercise Physiol 49:107

3. Green R, Rojas J, Sundell H 1979 Pulmonary vascular response to prostacyclin in fetal lambs. Prostaglandins 18:927

4. Hamasaki Y, Tai H, Said SI 1982 Hypoxia stimulates prostacyclin generation by dog lung in vitro. Prostaglandins Leukotrienes Med 8:311

5. Hyman AL, Bennett JT, Joiner PD, Chapnick BM, Mathe A, Kadowitz PJ 1976 Pulmonary vascular responses to arachidonic acid in intact dogs. Clin Res 24:53

6. Hyman AL, Mathe AA, Leslie CA, Mathews CC. Bennett JT, Spannhake E, Kadowitz PJ 1978 Modification of pulmonary vascular responses to arachidonic acid by alterations in physiologic state. J Pharmacol Exp Ther 207:388

7. Kadowitz PJ, Gruetter CA, McNamara DB, Gorman RR, Spannhake EW, Hyman AL 1977 Comparative effects of endoperoxide $\mathrm{PGH}_{2}$ and an analog on the pulmonary vascular bed. J Appl Physiol Respir Environ Exercise Physiol 42:953

8. Leffler CW, Desiderio DM, Wakelyn CE 1981 Preparation of biological fluids for simultaneous analysis of prostaglandin cyclooxygenase synthesized compounds by gas chromatography with electron capture detection. Prostaglandins $21: 227$

9. Leffler CW, Hessler JR 1979 Pulmonary and systemic vascular effects of exogenous prostaglandin $\mathrm{I}_{2}$ in fetal lambs. Eur $\mathrm{J}$ Pharmacol 54:37

10. Leffler CW. Hessler JR 1981 Perinatal pulmonary prostaglandin production. Am J Physiol 241:H756

11. Leffler CW, Hessler JR, Terragno NA 1980 Ventilation-induced release of prostaglandinlike material from fetal lungs. Am J Physiol 238: $\mathrm{H} 282$

12. Leffler CW, Passmore JC 1979 Contribution of prostaglandins to the regulation of pulmonary vascular resistance in adult cats and dogs. Prostaglandin Med $3: 343$

13. Lock JE. Olley PM, Coceani F 1980 Direct pulmonary vascular responses to prostaglandins in the conscious newborn lamb. Am J Physiol 238:H631

14. Moon MA, Lemen RJ, Quan SF 1983 Failure of acute hypoxia to alter pulmonary prostaglandin metabolism in dogs. Prostaglandins 25:615

15. Mullane KM, Dusting GJ, Salmon JA, Moncada S, Vane J 1979 Biotransformation and cardiovascular effects of arachidonic acid in the dog. Eur $J$ Pharmacol 54:217

16. Powell WS 1980 Rapid extraction of oxygenated metabolites of arachidonic acid from biological samples using octadecylsilyl silica. Prostaglandins 20:947

17. Rubin LJ, Lazar ID 1981 Influence of prostaglandin synthesis inhibitors on pulmonary vasodilatory effects of hydralazine in dogs with hypoxic pulmonary vasoconstriction. J Clin Invest 67:193

18. Said SI, Yoshida T, Kitamura S, Vreim C 1974 Pulmonary alveolar hypoxia release of prostaglandins and other humoral mediators. Science 185:1181

19. Scott E, Vaage J, Wiberg T 1979 Lack of release of prostaglandins from isolated perfused lungs during pulmonary hypertension and oedema. $\mathrm{Br} \mathrm{J}$ Pharmac 65:197

20. Snedecor GW, Cochran WG 1980 Statistical Methods, 7th ed. Iowa State University Press, Ames, pp 256-257

21. Spannhake EW, Hyman AL, Kadowitz PJ 1980 Dependence of the airway and pulmonary vascular effects of arachidonic acid upon route and rate of administration. J Pharmacol Exp Ther 212:584

22. Terragno NA, McGiff JC, Smigel M. Terragno A 1978 Patterns of prostaglandin production in the bovine fetal and maternal vasculature. Prostaglandins 16:847

23. Tyler T, Wallis R, Leffler C. Cassin S 1975 The effects of indomethacin on the pulmonary vascular response to hypoxia in the premature and mature newborn goat. Proc Soc Exp Biol Med 150:695

24. Vaage J. Bjertnaes J, Hauge A 1975 The pulmonary vasoconstrictor response to hypoxia: effects of inhibitors of prostaglandin biosynthesis. Acta Physiol Scand 95:95

25. Vaage J, Wiberg T, Bjertnaes L, Hauge A, Teig V, Gautvik K 1976 The effect of alveolar hypoxia on pulmonary biosynthesis of prostaglandins. Acta Physiol Scand Suppl 440:172

26. Voelkel NF, Gerber JG, McMurtry IF, Nies AS, Reeves JT 1981 Release of vasodilator prostaglandin $\mathrm{PGI}_{2}$ from isolated rat lung during vasoconstriction. Circ Res 48:207

27. Weir EK, McMurtry IF, Tucker A, Reeves JT, Grover RF 1976 Prostaglandin synthetase inhibitors do not decrease hypoxic pulmonary vasoconstriction. J Appl Physiol 41:714

28. Weir EK, Reeves JT, Grover RF 1974 Meclofenamate and indomethacin augment the pulmonary pressor response to hypoxia and exogenous prostaglandin $F_{2 \alpha}$. Physiologist 17:355

29. Wiberg T, Vaage J, Bjertnaes J, Hauge A, Gautvik KM 1978 Prostaglandin content in blood and lung tissue during alveolar hypoxia. Acta Physiol Scand $102: 18$

\title{
Vasopressin Concentration in Amniotic Fluid as an Index of Fetal Hypoxia: Mechanism of Release in Sheep
}

\author{
RAYMOND I. STARK, SALHA S. DANIEL, M. KAZIM HUSAIN, ULANA M. SANOCKA, \\ ALAN B. ZUBROW, AND L. STANLEY JAMES
}

Division of Perinatal Medicine, Departments of Pediatrics, Obstetrics and Gynecology, and Anesthesiology, College of Physicians and Surgeons, Columbia University, New York, New York 10032

\section{Summary}

Hypoxia is a potent stimulus to the release of vasopressin in fetal sheep, and plasma concentrations of the hormone correlate inversely with fetal oxygenation. Since the fetal kidney contributes to vasopressin clearance, we propose that measurement of

Received for publication September 19, 1983

Address correspondence to Raymond I. Stark, M.D., Division of Perinatal Medicine, College of Physicians and Surgeons, Columbia University, New York, NY 10032.

This work was supported in part by Grant HD-13063 from the National Institutes of Health. increased amounts of vasopressin in amniotic fluid would be indicative of fetal hypoxia. Therefore, we measured concentrations of vasopressin in amniotic fluid under resting conditions, during and after fetal hypoxia, and with intravenous and intraamniotic administration of vasopressin in 15 chronically instrumented fetal lambs between 111 and 141 days gestation. In the resting state, mean $( \pm \mathrm{SE})$ vasopressin concentrations in amniotic fluid $\left(1.6 \pm 0.3 \mathrm{pg} \mathrm{ml}^{-1}\right)$ did not differ from those in maternal $\left(1.4 \pm 0.4 \mathrm{pg} \mathrm{ml}^{-1}\right)$ or fetal $\left(1.8 \pm 0.2 \mathrm{pg} \mathrm{ml}^{-1}\right)$ plasma. Following exposure of the ewe to $10 \% \mathrm{O}_{2}$ or partial occlusion of the umbilical cord, vasopressin concentrations in fetal plasma in- 